ISSN 2237-258X

\title{
BENJAMIN CONSTANT E A PROPAGANDA EDUCACIONAL POSITIVISTA: ALGUNS APONTAMENTOS
}

\author{
Benjamin Constant and positive educational advertising: some points
}

\author{
Benjamín Constant y propaganda en la educación positivista: algunas notas
}

João Carlos da Silva*

\begin{abstract}
Resumo
Benjamin Constant Botelho de Magalhães (1836-1891), embora tenha participado diretamente do processo de constituição da república, ainda é pouco conhecido entre os historiadores da educação, não recebendo o devido tratamento pela historiografia educacional brasileira. Neste artigo discutimos Benjamin Constant, no limiar do século XIX, apresentado pela historiografia, especialmente entre os positivistas, como o Fundador da República. Verificamos a existência de estudos que centram abordagens biográficas, isto é, que se dedicam a enfatizar a trajetória histórica do autor com poucas referências sobre sua atuação no campo educacional. Pairam dúvidas quanto à denominação mais adequada, entre o Benjamin Constant militar ou pedagogo, ou seja, homem da guerra ou educador.
\end{abstract}

PALAVRAS-CHAVE: Benjamin Constant. Positivismo. Educação

\begin{abstract}
Benjamin Constant Botelho de Magalhães (1836-1891), although he participated directly in the process of constitution of the republic, is still little known among historians of education, not receiving due treatment by Brazilian educational historiography. In this article we discuss Benjamin Constant, on the threshold of the nineteenth century, presented by historiography, especially among the positivists, such as the Founder of the Republic. We verified the existence of studies that focus on biographical approaches, that is, that are dedicated to emphasize the historical trajectory of the author with few references about his performance in the educational field. There are doubts as to the most appropriate denomination, between the military Benjamin Constant or pedagogue, that is, war man or educator.
\end{abstract}

KEYWORDS: Benjamin Constant. Positivism. Education

\section{Resumen}

Benjamin Constant Botelho de Magalhães (1836-1891), aunque ha participado directamente en el proceso de constitución república no es muy conocido entre los historiadores de la educación, no conseguir un tratamiento adecuado por la historiografía la educación brasileña. Este documento analiza Benjamín Constant, en el umbral del siglo XIX, presentado por la historiografía, especialmente entre los positivistas, como la Fundación de la República. Verificamos la existencia de estudios que se centran los enfoques biográficos, que se dedica a hacer hincapié en la trayectoria histórica del autor con pocas referencias a su papel en el campo educativo. Hay dudas sobre el término más apropiado, entre Benjamin Constant militar o educador, o el hombre de guerra o educador.

\footnotetext{
*Pós-doutorado pela Universidade Estadual do Sudoeste da Bahia/UESB. Atualmente é professor no Colégio de pedagogia e do Mestrado em Educação da Universidade Estadual do Oeste do Paraná, UNIOESTE, Campus de Cascavel. E-mail: jcsilva05@terra.com.br
} 
PALABRAS CLAVE: Benjamín Constant. El positivismo. La educación

\section{INTRODUÇÃO}

As pesquisas acerca do positivismo continuam abrindo espaços para novos discursos, enfoques, recortes e leituras, momento em que o governo atual elege como slogan "ordem e progresso". No Brasil, o positivismo, em sua faceta mais ortodoxa, desenvolveu-se por intermédio das interpretações de Miguel Lemos ${ }^{\mathrm{i}}$ (1854-1917) e Teixeira Mendes ${ }^{\text {ii }}$ (1855-1927), e Benjamin Constant (1836-1891), fundadores da Igreja Positivista do Brasiliii (IPB), ao marcarem as posições oficiais do Apostolado Positivista do Brasil ${ }^{\text {iv }}$ (APB), cuja fundação é datada de 1876.

Com sua institucionalização definitiva, em 1881, seus seguidores iniciaram intensas atividades, sobretudo nas duas últimas décadas do Império e que se estenderam ao longo da Primeira República. Foi nessa época que o APB centrou esforços na formação da opinião pública, bem como, na tentativa de influenciar nas tomadas de decisões do governo, naquilo que consideravam como seu projeto educativo, isto é, a regeneração da humanidade. Na perspectiva dos seus seguidores o mundo vivia em crise de natureza moral, cabendo a esta filosofia regenerar os indivíduos.

Os republicanos constituídos pelas mais diferentes posições também viam nas ideias gerais do positivismo uma força de modernização, que atingiria todas as instituições da época. Sobre a presença do apostolado na instauração da República, Emília Viotti da Costa (1985) considera que sua influência na sociedade brasileira foi muito restrita, ainda que as ideias positivistas difundissem aquilo que se poderia chamar de concepção positivista de vida.

No final do Império, o contingente de positivistas era significativo entre os intelectuais. Muitos exaltavam os ensinamentos de Augusto Comte, com pouca clareza de seu conteúdo, outros reconheciam o caráter inovador dessa filosofia, expressando suas ideias políticas, econômicas e educacionais. Uma minoria se declarava ortodoxa, mas todos expressavam um objetivo comum: derrubar a Monarquia. A fundação do Partido Republicano, em 1870, foi o momento em que o ideal republicano se transformou em um projeto mais orgânico, com um conjunto de propostas.

No final do século XIX houve um expressivo crescimento do positivismo, ganhando cada vez mais adeptos nos diferentes segmentos da sociedade brasileira: na academia, na imprensa, nos quartéis, nas escolas, no parlamento, além de comerciantes e industriais. Segundo Paim (1981a), o APB exerceu influência mais efetiva depois da proclamação da República, com relativo sucesso, ao ser representado por Demétrio Ribeiro no Ministério da Agricultura, ainda que com algumas reservas e, Benjamin Constant, no Ministério da Guerra, posteriormente no Ministério da Instrução, quando da formação do Governo Provisório.

Tema recorrente entre os positivistas foi a necessidade de elaborar e propor medidas de natureza pedagógica, social e política para inserir os escravos recém-libertos e os imigrantes na vida republicana. Com esse intuito, a Igreja Positivista saiu em defesa de uma renovação políticosocial em torno de temas como educação, saúde, problemas sociais, processo de produção, organização do Estado, jornada de trabalho, proteção social, condições de trabalho e bem-estar social do trabalhador.

No Brasil, a entrada e a expansão da doutrina positivista no período pré-republicano ocorreram pela imprensa, no parlamento, nas escolas, na literatura e na academia, em suas diferentes formas de adesão, produzindo um clima de entusiasmo por seu conteúdo de 
modernização das ideias. Sua disseminação no campo educacional deu-se, também, nos documentos oficiais em decorrência das reformas educacionais no Colégio Pedro II, feitas por Benjamin Constant.

Neste artigo temos por objetivo pontuar elementos acerca do ideário republicano e do processo de modernização nacional, levando em conta a presença de Benjamin Constant e seu papel jogado na correlação de forças que instituíram a República e as ideias educacionais do período.

\section{Benjamin Constant: o homem}

Benjamin Constant Botelho de Magalhães (1836-1891) nasceu no dia 18 de outubro, em São Lourenço, Niterói, Rio de Janeiro. Filho do português Leopoldo Henrique Botelho de Magalhães, primeiro-tenente em Portugal, e Bernardina Joaquina da Silva Guimarães. Seguiu carreira militar, dedicando-se ao exercício do magistério, como professor de matemática. A matriz de suas idéias está em Augusto Comte (1789-1857), do qual foi discípulo e divulgador. Teve seu primeiro contato com a obra do filósofo francês, ao ler o Systeme de politique positive ainda como estudante da Escola Militar.

A questão do ensino ocupou espaço importante no conjunto de suas ideias, sendo um dos fundadores do Apostolado Pozitivista do Brasil, ao lado de Miguel Lemos e Teixeira Mendes, em 1876. Entre as teses do Apostolado Positivista estavam a instalação e manutenção da ditadura republicana, a elaboração de um projeto constitucional, a separação da Igreja do Estado, uma ampla reforma no ensino e a liberdade como princípio universal fundamentado na ideia de Ordem e do Progresso.

Figura 1 - Fachada da Igreja Positivista do Brasil

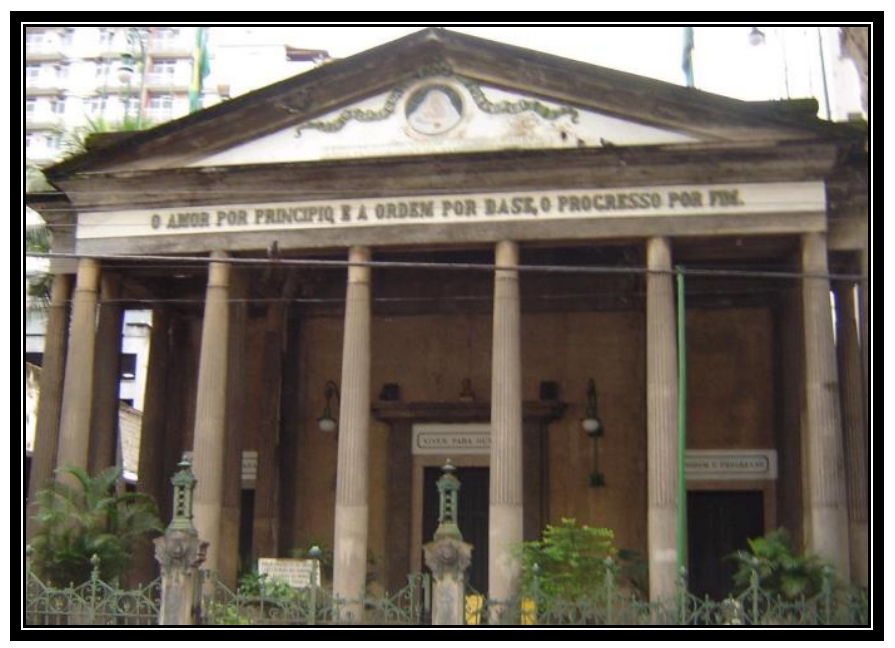

Fonte: Autor (2007).

O Museu Casa de Benjamin Constant está situado em Santa Teresa, um dos bairros mais pitorescos da cidade do Rio de Janeiro, construída no alto de ampla área verde, que no século XIX permitia a visão das habitações da parte baixa da cidade e da Baía de Guanabara. Em 1982, tornou-se Museu Casa de Benjamin Constant pela então Secretaria do Patrimônio Histórico e 
Artístico Nacional / Fundação Pró-Memória, reconstituindo o ambiente familiar e o contexto sócio-cultural.

Figura 2 - Fachada do Museu Casa de Benjamin Constant

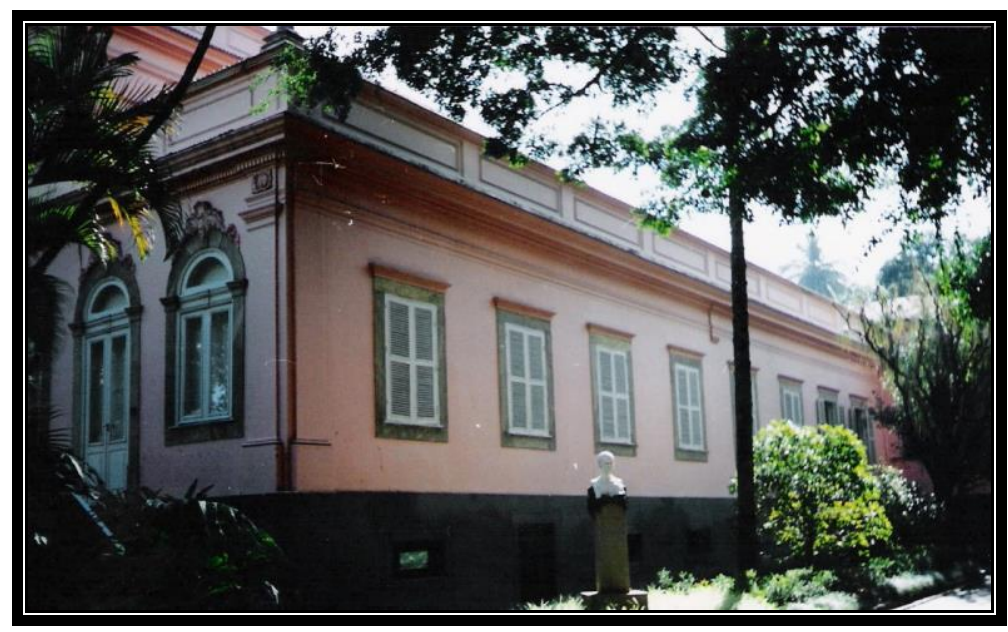

Fonte: Autor (2007)

No local estão guardados documentos doados por familiares constituindo o Arquivo Histórico e à Biblioteca do museu, que já conta com aproximadamente 26.427 documentos e 3.000 fotografias, distribuídos pelos fundos: Benjamin Constant, José Bevilaqua (genro), Pery Constant Bevilaqua (neto) e Família Benjamin Constant. O acervo que reúne documentos privados e oficiais de três gerações, tornando-o um arquivo singular, totalmente inventariado e aberto ao público e estudiosos de diversos temas.

Cobrindo um período de tempo contínuo desde 1837, data de nascimento de Benjamin Constant, até 1990, ano de falecimento de Pery Constant Bevilaqua, importante fonte de pesquisa para várias áreas de conhecimento: História do Brasil, Antropologia, Pedagogia, Filosofia, Sociologia, Política etc., mas especificamente, sobre os temas: Proclamação da República, Políticas Educacionais no $2^{\mathbf{o}}$ Reinado, Governo Provisório, Positivismo, Revolução de 30, Militarismo no Brasil, Golpe de 64, Ensino Militar, entre outros.

Teixeira Mendes atribui a Benjamin Constant o idealizador da expressão "Ordem e Progresso" inscrito na Bandeira Nacional que teria sido bordado por uma de suas filhas inspirado no ideal positivista, a partir da máxima "O amor por princípio, à ordem por base e o progresso por fim". Por proposta do positivista Demétrio Ribeiro, Benjamin recebeu o título de Fundador da República Brasileira. Foi professor e diretor do Instituto dos Meninos Cegos, do Rio de Janeiro, durante 20 anos, desde 1891, denominado Instituto Benjamin Constant.

Em 19 de abril de 1890, criado o Ministério da Instrução Pública, Correios e Telégrafos, foi confiada a Benjamin Constant, que correspondia aos mais caros projetos políticos dos positivistas. Na condição de ministro, dedicou-se à organização da instrução pública, encaminhando importantes reformas em todos os níveis de ensino. Constant não foi um intelectual de vários escritos, limitando-se a escrever um trabalho de conclusão do curso de bacharelado em matemática e ciências naturais, intitulado Theoria das Quantidades Negativas, publicada em 1868, sem muita repercussão no meio acadêmico, além de alguns fragmentos de 
poemas dedicados à sua esposa. Suas percepções sobre os acontecimentos de sua época estão registradas nas cartas recebidas e enviadas por ele a parentes próximos quando de sua participação na Guerra do Paraguai (1865-1870).

\section{Benjamin Constant na historiografia brasileira}

Na vasta produção historiográfica sobre o final do século XIX, são poucos os estudos dedicados a atuação de Benjamin Constant. Teixeira Mendes em seu Esboço sintético da vida e obra de Constant (1913), uma publicação do Apostolado Positivista do Brasil, talvez a biografia mais completa acerca de Constant.

Em O ideal republicano de Benjamin Constant (1936), do mesmo autor, expressa em seu conteúdo, forte exaltação de Constant, colocando-se como o principal articulador e fundador da República, uma homenagem aos relevantes serviços prestados ao país. Roberto Macedo (1936), por sua vez, em $O$ Fundador da República, prefaciado por Ivan Lins, estudioso do positivismo, presta suas homenagens, destacando no epílogo do livro, algumas frases que, segundo ele sintetizam a imortalidade de Constant entre elas destacamos: "[...] um dos tipos mais perfeitos da Humanidade, um misto de herói, santo e sábio, ou então, um exemplo às gerações futuras, modelo de civismo, exemplo de altruísmo" (MACEDO, 1936, p.77-78).

O historiador Renato Lemos, em Benjamin Constant: Vida e História (1999), resultado de sua tese de doutorado, é considerado um estudo de referência. Coloca-se na perspectiva dos estudos biográficos, munido de farta documentação, em especial fotografias, alcançadas junto ao Museu Casa de Benjamin Constant, no Rio de Janeiro. Esta obra retrata as dificuldades do quotidiano familiar ao mesmo tempo em que revela o homem de ação, o herói mítico.

Em As Cartas de Guerra, publicada pelo mesmo autor, mantêm-se fiel aos estudos sobre a trajetória de Constant, ao transcrever as cartas enviadas e recebidas por Constant à família, procurando retratar suas experiências de guerra, como militar e político, quando de sua participação na Guerra do Paraguai (1865-1870). Com estas duas obras, Lemos retrata um Constant humanizado, envolvido nos embates e nos acontecimentos de sua época, centrando no indivíduo sem maiores incursões pelo contexto econômico, social e político de sua época.

O livro de José Murilo de Carvalho, A formação das almas: o imaginário da república no Brasil (1990) merece destaque nos estudos sobre o processo da gênese da República no Brasil, ao mostrar as tramas, os embates a as contradições que envolveram a constituição do imaginário republicano, sobretudo na forma inovadora em que o pesquisador se utiliza das fontes iconográficas, como monumentos, caricaturas de jornais, revistas e obras de arte.

Em suas análises Benjamin Constant aparece como militar pacifista, com ideias liberais, que disputavam a hegemonia do poder, mas colocando-se na vertente do positivismo. Afirma o autor: "Como positivista, embora não ortodoxo, nada tinha de militarista, repugnava-lhe a ideia do predomínio da força na política. Pacifista, sonhava com o fím dos exércitos, com o recolhimento de todas as armas ao museu da história." (CARVALHO, 1990, p.41). Neste sentido, Constant aparece na condição de herói que se colocava como o responsável pela disseminação do mito da República.

Silva (1998) em sua dissertação refere-se, em seu título, Constant como o filósofo, o republicano e educador, portador de um projeto de Brasil, o articulador das " [...] transformações sociais e políticas de seu tempo, que levou a termo os interesses e os anseios povo pela 
consolidação dos sonhos liberais como a separação entre Igreja e Estado, laicização da educação, cemitérios, registros de nascimentos". (p.4).

Maria Teresa Cartolano Penteado (1994), em sua tese intitulada Benjamin Constant e a Instrução pública no início da primeira república, que contrapõe- se às abordagens que privilegiaram os estudos de recortes marcadamente biográficos em que analisa sua proposta pedagógica presente no Regulamento de 8 de novembro de 1890, (Decreto Lei N. 981).

O século XIX foi um período de intensos debates em torno da organização de um sistema público de ensino, principalmente na Europa, com repercussões no cenário brasileiro. Constant elege a educação como instrumento de modernização em relação ao pensamento educacional do Império, identificadas como sendo as forças conservadoras. Essas forças eram por ele consideravas como sendo os entraves para o encaminhamento de um projeto de modernização brasileira, projeto fundamentado no ideário da liberdade econômica, como eixo para a ordenação de um poder nacional de exaltação dos ideais marcados pelo progresso, mas sem renunciar às liberdades.

A contribuição do positivismo comtiano, ao reforçar uma ordem de liberdade política e econômica, propunha a necessidade de oferecer suporte ao progresso social, face ao avanço da indústria. Neste contexto, caberia à educação a tarefa de auxiliar na formação dos hábitos, das mentes, do caráter, dos padrões morais e intelectuais em consonância com os acontecimentos.

Aos olhares dos positivistas, as mulheres e os proletários representavam a sabedoria natural, desinteressada, carregados de amor e virtude. Assim, teriam uma missão importante de disseminar a paz e o amor universal, portanto, desempenhando um papel de grande importância na constituição da harmonia social.

O final do século XIX, início do século XX, foi um tempo marcado por tensões, em que diferentes projetos sociais de transformação social se colocavam de maneira muito clara e diversa, expressos nas propostas em torno da educação. De um lado, a burguesia e, de outro, o proletariado. Jornalistas, intelectuais, educadores, fazendeiros, políticos da época elaboravam seus discursos, com forte tendência liberal- conservadora, convergindo para a necessidade da defesa da ordem pública.

\section{Benjamin Constant e a propaganda positivista}

A partir de 1880, novas palavras e expressões passaram a fazer parte da propaganda e dos discursos políticos da época: "anarquia mental", "pedantocracia", "os mortos governam os vivos", "a pátria brasileira", "incorporação do proletariado" tornando-se comuns, também na imprensa. Desde 1850 eram percebidas, na Escola Militar do Rio de Janeiro, as repercussões da doutrina comtiana, fazendo do positivismo científico título de monografias acadêmicas em diferentes estabelecimentos de ensino ${ }^{1}$.

\footnotetext{
${ }^{1}$ Ivan Lins dá como certo o ano de 1844 como sendo o da entrada do positivismo no Brasil. Na Escola Politécnica e na Escola Militar do Rio de Janeiro, havia já um certo grau de influência positivista. Natural que fosse nessas escolas, local em que o positivismo estivesse melhor representado e mais ativo, por serem escolas de ciências exatas e naturais, O Colégio Pedro II, a Escola Militar, a Escola da Marinha, a Escola de Medicina e a Escola Politécnica. Em 1857, Benjamin Constant Botelho de Magalhães, professor de Matemática, seu mais importante divulgador, conhecido pela sua capacidade formadora perante os mais jovens, fez conhecer o positivismo em sua dimensão social e religiosa.
} 
A partir de 1870, as agitações abolicionistas espalharam-se por todo o país, especialmente a partir de São Paulo, Rio de Janeiro e Rio Grande do Sul. A figura feminina foi uma das alegorias utilizadas pela Revolução Francesa também utilizada pelo Apostolado. Como forma de promover a legitimação do futuro regime republicano, difundiam símbolos e alegorias, como: a bandeira, a mulher e o hino, construindo um novo imaginário social.

A propaganda positivista, no Brasil, expressava um profundo entusiasmo pela França, à medida que se aproximava o centenário da sua revolução, em 1889. Não é por acaso que a mudança do regime coincidiu com a referida data. Na direção desse acontecimento, em 1880, sociedades abolicionistas foram fundadas, com a finalidade de organizarem suas lutas, entre elas a Sociedade Brasileira contra a Escravidão e a Associação Central Emancipacionista. Nesse contexto de ampliação e luta pela abolição do trabalho escravo, o Apostolado Positivista reforçava suas publicações em favor da abolição e fortalecia a organização da Sociedade Positivista do Rio de Janeiro.

A difusão do positivismo inspirou educadores, políticos e intelectuais, servindo como instrumento ideológico na disseminação do poder vigente. A música também teve papel importante na propagação e difusão do nacionalismo, sobretudo com a proclamação da República. O positivismo inspirou título de discos e de músicas, sobretudo na voz e na composição de Noel Rosa. O positivismo também tornou título de discos e músicas: Positivismo em Enciclopédia musical brasileira - Noel Rosa por Noel Rosa e Sinhô por Mário Reis - Mário Reis / Noel Rosa / Sinhô (2000); Positivismo em Arvore da Vida - Jorge Mautner e Nelson Jacobina - Jorge Mautner (1988); Positivismo em Uma Rosa para Noel - 50 anos depois - Noel Rosa (1987); Positivismo em Wilson, Geraldo, Noel - João Nogueira (1981); Positivismo em História musical de Noel Rosa - Marília Batista / Noel Rosa 1963); Positivismo em Canções de Noel Rosa cantadas por Noel Rosa - Noel Rosa (1955); Positivismo - c/ Noel Rosa em Noel pela primeira vez - volume 4 - Noel Rosa (2000).

O samba, Positivismo, de 1933, de autoria de Noel Rosa, revela a presença da filosofia positivista no meio cultural mais popular do Brasil, a música e retrata uma amada que transgrediu o fundamento básico de tal filosofia:

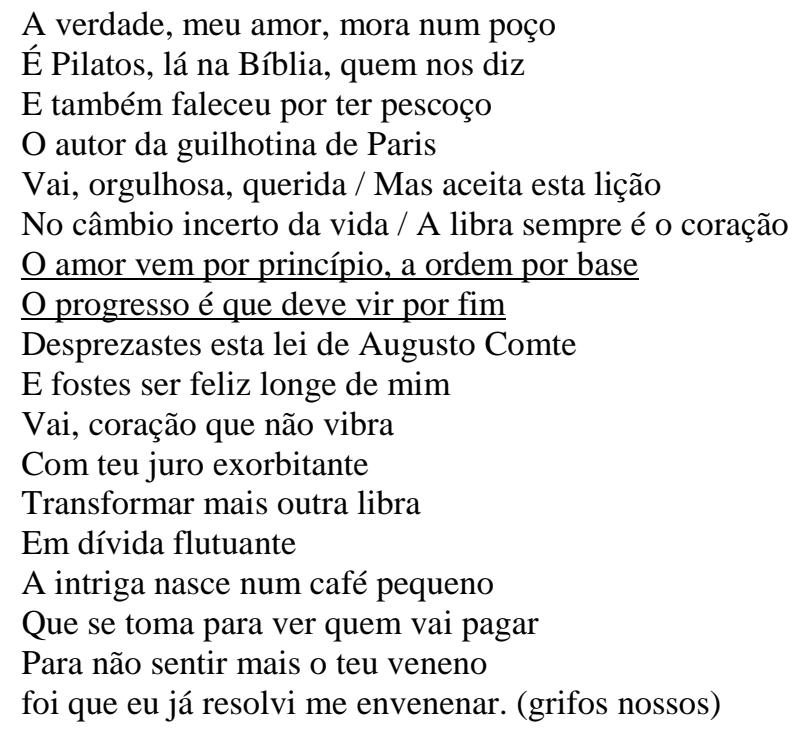


Outro indicador do crescimento do positivismo no Brasil consistiu nas reformas educacionais, notadamente do ensino primário e secundário, na organização do ensino superior profissional e no veto sobre a estruturação da universidade.

Em São Paulo o positivismo teve forte repercussão em razão de personalidades como Luís Pereira Barreto, cuja influência se fazia sentir na imprensa. Foi a partir de 1870 que o positivismo ampliou sua força, saindo dos limites de São Paulo e Rio de Janeiro, difundindo-se para outras regiões do Brasil e tornando-se modismo nacional (TRINDADE, 1999). Nesse âmbito, as reformas empreendidas por Benjamin Constant foram as mais importantes na fase do Governo Provisório. Tais reformas sofreriam alguns ajustes, mas mantiveram seus pressupostos teóricos, já que eram caracterizadas por teses liberais não intervencionistas e pela formação moralizadora, denominadas por Paim como legado pombalino (1987, p. 560). Após ser constituído enquanto organização política, o apostolado conquistou espaço na grande imprensa.

Em carta dirigida ao redator-chefe da Gazeta de Notícias, em 29 de março de 1881, Miguel Lemos (1882, p. 58) assim agradece tal disposição: “A intervenção jornalística que V.Sa. põe a nossa disposição torna-se um elemento importantíssimo para realizar este duplo aspecto que apresenta a ação possível e necessária do Positivismo sobre a opinião pública [...]”.

Ao fazer do positivismo uma filosofia moralizadora do regime republicano, os representantes do AP negavam toda prática de corrupção, de roubo e violência. Com a Proclamação da República, procuraram intervir nas principais decisões do Governo Provisório, oferecendo sugestões, muitas vezes exigindo providências emergenciais. Desejavam que instituíssem não apenas a República, mas uma ditadura republicana, isto é, um governo forte, como saída diante do contexto de radicalização das posições e do enfrentamento das classes sociais em que o mundo vivia.

Na segunda metade do século XIX, o culto ao trabalho talvez se constituiu no principal ideário do mundo capitalista, princípio também exaltado pelo Apostolado Positivista no ensaio "Hino ao trabalho" (MENDES,1889), inspirado pelo otimismo da livre concorrência e pela defesa das liberdades como fontes imprescindíveis para o progresso humano

O positivismo significou para as elites brasileiras, no final do século XIX, um novo paradigma, que colocaria o país na rota da modernização, numa dinâmica regida pelas transformações nas relações de trabalho. O Apostolado estava voltado aos mais diversos temas da época, como abolição da escravatura, Constituição Federal, política externa, saúde pública, separação do Estado da Igreja, papel da mulher na sociedade, a situação das populações indígenas, ortografia da língua portuguesa, legislação trabalhista e educação.

A reforma das instituições políticas foi uma das principais bandeiras do Apostolado, no qual cabia à educação a tarefa de auxiliar a formação de novos hábitos, bem como da mentalidade e do caráter, disseminando assim padrões morais e intelectuais. Isto porque, para Comte, o mundo vivia uma crise moral que abalava o mundo moderno, que exigia mudanças. Para o filósofo francês não se tratava de uma crise social devida ao processo de introdução da maquinaria na produção e sua consequência social, como alertava Marx, mas, uma crise exclusivamente de natureza moral e intelectual dos indivíduos. As lutas de classe na visão dos positivistas eram decorrentes da ausência de uma educação pacifista na sociedade, que deveria atingir a todos os setores e classes.

Segundo Paim (1997), a presença do positivismo no Brasil pode ser distinguida em duas fases a saber: da propaganda e da sua prática. O positivismo, ao tornar-se filosofia de Estado ou para-estatal, sobretudo durante o Governo Provisório (1889-1891), passou a exercer influência nos encaminhamentos das principais decisões políticas tomadas, especialmente nas três primeiras 
décadas da República. Ivan Lins (1967, p. 11), considera que a difusão do positivismo no Brasil não pode ser resumida somente à ação de Teixeira Mendes, Miguel Lemos e Benjamin Constant, fundadores da Igreja Positivista. Alguns até aderiram às ideias gerais da doutrina de Comte e seu método, sem levá-las à prática.

As intervenções públicas do Apostolado, nas discussões educacionais davam-se por diferentes meios. Através de livros, folhetos, periódicos, que compunham uma farta publicação de material, oriundo da Igreja Positivista do Brasil, com sede no Rio de Janeiro, dos núcleos positivistas regionais por diferentes Estados e dos artigos em jornais escritos por membros e simpatizantes da Igreja.

As correspondências trocadas entre positivistas religiosos brasileiros e estrangeiros também constituem fontes importantes para compreender as ações do Apostolado no Brasil ${ }^{\mathrm{v}}$. $\mathrm{O}$ conjunto das publicações se completava com traduções das obras de Augusto Comte e de outros autores indicados pelo próprio filósofo francês, para a formação de mentes positivistas, e que, portanto, deveriam compor o acervo da Biblioteca Positivista ${ }^{\mathrm{vi}}$. Comte, em Apelo aos Conservadores, (1891), coloca os positivistas como os verdadeiros representantes da Humanidade, portanto, em quem se devia confiar os únicos capazes de construírem, através de seus poderes políticos e autoridade, uma ordem justa, equilibrada e estável ${ }^{\mathrm{vii}}$.

Miguel Lemos, no Resumo Histórico do Movimento Positivista no Brasil viii (1881), apresenta a propaganda positivista e sua ação política nos encaminhamentos da República ${ }^{\text {ix }}$. Em extrato da Carta, o chefe da Igreja Positivista da França, Pierre Laffitte, assim confere a Miguel Lemos o título de Diretor Provisório do Positivismo no Brasil: "Vu l'âge et lê title d'aspirante au sacerdoce de l'Humanité, je crois que vous devez avoir lê titre de directeur provisoire du Positivisme au Brésil, quoique vouz l'ayez réellement en fait, et bien heureusement pour le sevice de notre grande Cause" $x$.

Convertendo-se à ortodoxia positivista, Miguel Lemos, juntamente com Teixeira Mendes, teve como propósitos principais, desenvolver o culto, organizar o ensino da doutrina e intervir oportunamente nos negócios públicos ${ }^{\mathrm{xi}}$. Opunham-se às posições mais heterodoxas, lideradas na época por Emile Littré, considerados por aqueles como passivos, pois não assumiam a integralidade da filosofia comtiana ${ }^{x i i}$.

Estabelecida nos padrões da filosofia positivista, passou a denominar-se, em 1878, Sociedade Positivista do Rio de Janeiro, filiada à Igreja Positivista da França, sob a direção de Pierre Laffitte, passando a imprimir um ritmo de ampla divulgação do positivismo. Teve como primeiros sócio-fundadores, Oliveira Guimarães, Benjamin Constant, Álvaro de Oliveira, Joaquim Ribeiro de Mendonça, Oscar Araújo, Miguel Lemos e R. Teixeira Mendes xiii. Miguel Lemos assim expressa o sentido do Apostolado:

O Positivismo inaugurava assim em nossa pátria as belas tradições das escolas de Paris e Londres, solícitas sempre em protestar em nome da moral humana e da dignidade nacional, contra os abusos do industrialismo desregrado que domina nas relações do Ocidente com o resto das populações da terra. (LEMOS, 1882, p. 28)

Em 5 de setembro de 1878, em Ata da primeira sessão comemorativa da morte de Augusto Comte, celebrada no Rio de Janeiro. Em seu lugar é aclamado o Sr. Joaquim Mendonça como presidente provisório da Sociedade Positivista, em substituição ao Dr. Oliveira Guimarães, falecido em janeiro de 1878, ocasião em que se deliberou sobre assuntos importantes, que 
marcariam, de maneira definitiva, a organização, estruturação e ação do Apostolado no Brasil, a saber:

[...] fundar uma associação com o fim de propagar e desenvolver a doutrina positiva por todos meios ao alcance dos sócios.

[...] aceitar quaisquer donativos, quer em dinheiro quer em livros, com tanto que estas sejam os da Biblioteca Positivista de Augusto Comte ou publicações da Escola Positivista.

[...] que cada sócio concorra desde já com quantia de dois mil réis no mínimo, pagos no começo de cada mês.

[...] que os sócios presentes e representados nesta sessão contrairão o compromisso solene de em artigos que se começarão a publicar na imprensa periódica o mais tardar até o mês de Arquimedes (março e abril) do próximo ano, de propagar o Positivismo, consagrando-se sobre tudo a demonstrar a aptidão desta doutrina para educar e moralizar a sociedade

[...] que os sócios contrairão, sempre que for possível, o mesmo compromisso de propaganda pela imprensa periódica.

[...] Que estes escritos serão submetidos a aprovação de dois consócios antes de publicados, afim de garantir a perfeita solidariedade dos demais membros a Associação com as opiniões emitidas pelo autor. (LEMOS, 1882, p. 55-56)

A Igreja Positivista do Brasil, fundada em 19 de César de 93 - 11 de maio de 1881 por Miguel de Lemos, está localizada à Rua Benjamin Constant, 74 - Glória, Rio de Janeiro. Sua sede, também conhecida como Templo da Humanidade, foi o primeiro edifício construído, no mundo, para difundir a Religião da Humanidade.

A primeira Circular data de 1881, assinada por Miguel Lemos, sendo recorrentes nestas circulares à divulgação dos princípios do Apostolado e das bases de organização da Igreja Positivista, assuntos que geralmente abria as circulares, acompanhadas por uma análise de conjuntura econômica e política em nível nacional e internacional. Encerravam as circulares apresentando um relatório financeiro da Igreja e publicação de suas contas bem como a divulgação com os títulos das últimas publicações. Os membros do apostolado utilizavam-se ainda deste espaço para expressar as propostas do apostolado para a educação brasileira, ao considerar que cabia aos positivistas o dever de esclarecer e alertar a população sobre os malefícios e os danos que as decisões do governo poderiam causar à sociedade.

A rigor, o progresso aparece aos olhares dos positivistas como um ponto fixo diante das tradições do passado das incertezas e das promessas do futuro, em que pessimismo e otimismo se entrecruzavam naquilo que anunciava a República e a abolição da escravatura.

Em direção ao projeto republicano, foram transferidas todas as expectativas salvacionistas, produzindo um contexto messiânico. O Marechal Manoel Deodoro da Fonseca, chefe do Governo Provisório, entre 1889 e 1891, expressava esse mesmo movimento ao defender a unidade nacional em torno dos interesses liberais da economia, promovendo uma ordem que justificasse a existência das classes sociais, fundada nos postulados positivistas, considerada a única filosofia capaz de regenerar a sociedade. Como analisa Mendes:

Portanto, o problema social consiste em tornar amável e mesmo cubiçável a pobreza, dignificando a ezistência operária, de tal módo que éla permita a compléta satisfação de nóssos atributos superiores, em vês de teimar em só ver a felicidade na opulência e na grandeza. E esse problema foi rezolvido por Augusto Comte, instituíndo a Religião da Humanidade. Na época, porem, que estamos considerando apenas éssa religião dezabrochava e as primeiras obras filozóficas do Supremo Regenerador penetrávão em 
nóssa Pátria. Benjamin Constant foi, pois, o hômem do seu tempo, olhando com menosprezo para uma função industrial subalterna (1913, p. 38-40).

Por indicação de Miguel Lemos e de Teixeira Mendes, Benjamin Constant, ao ocupar o posto de ministro de Guerra, adotou, por decreto de 19 de novembro, a bandeira com a divisa comtiana: "Ordem e Progresso". Demétrio Ribeiro, na época ministro da Agricultura, e Benjamin Constant, ministro da Guerra e, posteriormente, ministro da Instrução, não economizaram esforços, junto ao Marechal Deodoro para que tal decisão não fosse adiada, dada a urgência de instaurar uma ordem política liberal, anticlerical.

No movimento de modernização do Brasil, o positivismo no século XIX constituiu-se numa importante vertente de retificação do capitalismo, propondo a integração entre as classes e dedicando-se à ideia de incorporação dos indivíduos, sobretudo do proletariado. Essa dinâmica assinalava, ainda que embrionariamente, um novo tempo na relação capital versus trabalho.

$\mathrm{O}$ fim da monarquia, por sua vez, estava relacionado às disputas pelo poder político entre os diferentes segmentos das classes dominantes, envolvendo militares, cafeicultores, homens de negócios, fazendeiros tradicionais, e intelectuais. Esse processo punha o Brasil cada vez mais numa posição de destaque na divisão internacional de trabalho e no caminho dos fluxos de capital e de força de trabalho que se encaminhavam do Velho para o Novo Mundo (FAUSTO, 1982, p. 352).

A reforma educacional de Benjamin Constant para a escola primária no Distrito Federal foi inspirada pelas idéias positivistas a partir do regulamento em 8 de novembro de 1890 . $\mathrm{Na}$ condição de ministro, dedicou-se à organização da instrução pública, encaminhando importantes reformas em todos os níveis de ensino, como o ensino primário gratuito, livre e leigo no Distrito Federal; a exigência de diploma conferido pela Escola Normal para o exercício do magistério público; o ensino elementar organizado em três níveis: o primeiro para crianças de 7 a 13 anos e o segundo para jovens de 13 a 15 anos e o terceiro sobre a reorganização do Colégio D. Pedro II.

Sua maior preocupação era estabelecer um programa de organização da Escola Normal. Para tanto, criou e formulou o regulamento para o pedagogium da capital federal, que se tornou o centro de aperfeiçoamento do magistério e de propagação das novas idéias pedagógicas da República.

Como veículo de comunicação entre o professorado e o recém-criado Ministério da Instrução, foi organizada a Revista Pedagógica com a finalidade de publicar os atos e decretos acerca da instrução primária e secundária, disseminando as intenções das reformas e constituindo-se em um espaço de divulgação das ideias mais recentes de educadores nacionais e estrangeiros e dos métodos e estratégias de ensino por eles praticados. A formação de professores seria fundamentada no altruísmo, na paixão e no sentimento cívico. Assim, a ciência e a indústria assegurariam o progresso, enquanto a moral e o processo educativo garantiriam a ordem (CARTOLANO, 1994).

\section{CONSIDERAÇÕES FINAIS}

A educação, durante a Primeira República, teve como marco inicial a influência positivista na política educacional, a partir da atuação de Benjamin Constant em 1890-1891). Foi durante esse período que surgiram as escolas superiores livres, não dependentes do Estado, empreendidas por iniciativas particulares. Foi, também nesse período que surgiram os primeiros 
estabelecimentos de ensino superior no Brasil com o nome de universidade, sendo a do Rio de Janeiro, criada em 1920, e a de Minas Gerais, 1927, as que vingaram. Tratava-se de substituir o reino dos bacharéis, considerado inadequado ao novo tempo da técnica, marcado pela indústria e pela lavoura articulada à ciência, por uma formação de base mais prática e utilitarista. Com a emergência do autoritarismo republicano, foi abandonada a tradição liberal do Império.

As inúmeras reformas do ensino, o veto do positivismo em relação à universidade, a conservação do ensino superior como modalidade técnico-profissional e a difusão de uma pedagogia moralizante em substituição ao catolicismo foram alguns dos indicadores da ascensão do positivismo, portanto, das ações do apostolado e sua influência no decorrer da Primeira República.

Verificamos que a maioria dos trabalhos, enfatiza um aspecto do autor como: o militar, o fundador da república brasileira, o matemático, o professor, o idealista, o íntegro, o combatente na Guerra do Paraguai, o patriota ou o divulgador do positivismo, um dos republicanos históricos ao lado do Marechal Deodoro da Fonseca, Floriano Peixoto, Quintino Bocaiúva, enfim um dos vultos da história brasileira, além de ser considerado pelos seguidores do positivismo, exemplo a ser seguido pela juventude de sua época. Em muitas das publicações ainda pairam dúvidas quanto denominação mais adequada, entre o Benjamin Constant militar ou pedagogo, ou seja, homem da guerra ou educador.

Benjamin Constant e seus contemporâneos disseminaram a ideia de que a escola seria capaz de eliminar a crise e a violência que dominavam a sociedade. O projeto educacional do apostolado deve ser compreendido no conjunto de seus escritos político-filosóficos, ao reforçar uma nova concepção de homem, educação e sociedade, fundada no interesse da burguesia. Com relação à formação humana ocuparam-se em pensar e propor uma educação calcada no conteúdo moral. Com isso, havia um forte poder de moralização da formação para o trabalho e de estabelecimento de regras de convivência social. Esse discurso, muito presente naquela época, preocupava-se em propor uma regeneração da humanidade.

A formação desse homem marcaria um novo tempo educacional para o Brasil, caracterizado pela constituição, formação, desenvolvimento e incorporação de todas as camadas sociais. A plataforma política do apostolado visava fazer do Brasil uma democracia nos moldes burgueses. A construção desse modelo de nação, passava pela incorporação ou inclusão de massas de pessoas pelo processo de formação, o que não significava necessariamente passar pelos bancos escolares, isto é, pela escolarização. Nesse processo, a família aparecia como o primeiro agente formador e o ideário educacional, atribuindo à mulher presença marcante, como responsável pelo ensinamento dos hábitos de boa conduta, higiene e trabalho.

Os seguidores do apostolado demonstravam o firme propósito de modificar o ensino de seu tempo em contraposição ao pensamento católico, ainda preso às tradições da escolástica. Os dirigentes do apostolado defendiam um tipo de sociedade na qual o clero fosse afastado do comando do processo educativo, devendo ser colocado em seu lugar uma nova instituição, responsável pela difusão de uma nova filosofia educacional. Para eles, as escolas de seu tempo, isto é, praticadas no Império, estavam impregnadas pela corrupção, incompetência e, portanto, fracassavam em seus objetivos didático-pedagógicos, expressando a condição social que os indivíduos viviam.

A passagem do trabalho escravo ao trabalho livre, que produziu um processo de tensão, era compreendida pelos representantes do apostolado como um estado de "anarquia" mental e espiritual. Eles colocaram-se a favor da formulação de um projeto pedagógico vinculado ao 
processo de reconstrução nacional e, nesse contexto, a família, sobretudo, a criança, foi colocada no centro das ideias e das reformas educacionais entendidas como urgentes e necessárias.

O crescimento e o desenvolvimento do proletariado industrial apareciam como o principal problema social da época. Constant e seus seguidores não tinham dúvidas: não eram revolucionários, incitar as lutas de classes não fazia parte de seu pensamento. Para os positivistas, o proletariado deveria aceitar formas de submissão ao trabalho por meio do principio do altruísmo. Assim, deveriam ser moralizados e não eliminados. Nesse aspecto a família, particularmente a mulher deveria desempenhar papel essencial.

Longe de esgotar esta discussão, objetivamos contribuir com a historiografia da educação brasileira sobre um importante período de nossa história. Esperamos, ao menos, ter levantado novas hipóteses e questões para pesquisas futuras, e, concomitantemente, ter contribuído para a revisitação e a preservação das fontes educacionais, tão necessárias para entender o processo educacional brasileiro.

\section{REFERENCIAS}

BRASIL. Senado Federal. Decreto n. 981 - de 8 de novembro de 1890. Disponível em: <http://www.histedbr.fe.unicamp.br/navegando/fontes_escritas/4_1a_Republica/decreto\%209811890\%20reforma\%20benjamin\%20constant.htm>. Acesso em 15 10/2016.

ARTOLANO, M. T. P. Benjamin Constant e a instrução pública no início da República. Tese de Doutorado. Campinas/SP: UNICAMP, 1994.

CARVALHO, J. M. de. A formação das almas: o imaginário da república no Brasil. São Paulo, Companhia das Letras, 1990.

CARVAlho, J. M. COMTE, A. Apelo aos conservadores. Rio de Janeiro: Sede Central da Igreja Pozitivista do Brazil, 1899.

DELANEZE, Taís. As reformas educacionais de Benjamim Constant (1890-1891) e

Francisco Campos (1930-1932): o projeto educacional das elites republicanas. 2007. Tese de Doutorado. Universidade federal de São Carlos. Centro de educação e ciências humanas programa de pós-graduação em educação. São Carlos, SP.

FAUSTO, Boris. História geral da civilização brasileira. Tomo III: O Brasil republicano. 3. ed. São Paulo: Difel, 1982.

FÁVERO, M. de L. de A. (org.) Dicionário de educadores no Brasil: da Colônia aos dias atuais. RJ: MEC/INEP, Ed. UFRJ, 1999. 
LEMOS NETO, R. L. do C. Cartas da Guerra: Benjamin Constant na campanha do Paraguai. Rio de Janeiro: IPHAN, 1999.

. Benjamin Constant: vida e história. Rio de Janeiro: Topbooks, 1999.

LEMOS, Miguel. Resumo histórico do movimento positivista no brasil ano de 93 (1881). Rio de Janeiro: Igreja Pozitivista do Brazil, 1882.

LINS, Ivan. História do positivismo no Brasil. São Paulo: Companhia Editora Nacional, 1967.

MACEDO, Roberto. O fundador da república. Rio de Janeiro: Livraria São José, 1936.

MENDES, R. T. Benjamin Constant: esboço de uma apreciação sintética da vida e da obra do Fundador da República Brasileira. RJ: Apostolado Positivista do Brasil, nº 120. 1913.

. O ideal republicano de Benjamin Constant. RJ: Tipografia do Jornal do Commercio, 1936. pp. 131-141.

Os ensinos de Augusto Comte e a reforma do ensino - a propósito da correspondência trocada entre o Sr. Dr. Rivadávia Correia, Ministro do Interior e o Sr. Dr. Licínio Cardoso, sobre a reforma do ensino. Rio de Janeiro: Igreja e Apostolado Pozitivista do Brazil, 1914a.

- Pela humanidade: condições iniludíveis da Paz. Rio de Janeiro: Igreja e Apostolado Pozitivista do Brazil, 1914b.

- Os ensinos de Augusto Comte e a reforma do ensino. Rio de Janeiro: Igreja e Igreja Pozitivista do Brazil, 1914c. p. 8.

. As gréves, a órdem republicana e a reorganização social: Rio de Janeiro: Igreja e Igreja Pozitivista do Brazil, 1906. p, 8.

- O regime republicano e o respeito à dignidade do proletariado, especialmente o culto pela mulher proletária. Rio de Janeiro: Igreja e Apostolado Pozitivista do Brazil, 1917. P 4.

- Ainda a estinção da violência, tanto governamental como popular, e a política moderna, sobretudo republicana. Rio de Janeiro: Igreja e Apostolado Pozitivista do Brazil, 1912 
. O ensino primario official e a regeneração humana. Rio de Janeiro: Igreja e Apostolado Pozitivista do Brazil, $1913 b$.

. Hino do trabalho: extrahído do ensaio sobre culto-público. Rio de Janeiro: Igreja Apostolado Pozitivista do Brazil, 1889.

FREITAS, M. C. Historiografia brasileira em perspectiva. São Paulo: Contexto, 2000.

MACEDO, Roberto. Fundador da República. RJ: Livraria São José, s.d.

SILVA, C. M. S. da. Benjamin Constant Botelho de Magalhães: militar ou pedagogo? Revista Temas \& Debates -N. 5. Caxias do Sula, RS.

PAIM, A. (Org.). O apostolado positivista e a república. Brasília, DF: Universidade de Brasília, Câmara dos Deputados, 1981. (Col. Pensamento Político Republicano 2).

PAM, A. História das ideias filosóficas no Brasil. São Paulo: Grijalbo, 1987.

SILVA, W. S. Benjamin Constant: Filósofo, Republicano e Educador. Dissertação. (Mestrado em Ciência da Religião) Instituto Metodista de Ensino Superior. São Bernardo do Campo, SP, 1998.

TRINDADE, H. (Org.). O positivismo: teoria e prática. Porto Alegre: Ed. Universidade/UFRGS, 1999.

VIOTTI DA COSTA, E. Da monarquia à república: momentos decisivos. 3. ed. São Paulo: Brasiliense, 1985.

\section{Notas}

\footnotetext{
${ }^{\text {i }}$ Miguel Lemos (1854-1917), filho de uma oficial de Marinha, nasceu em Niterói, Rio de Janeiro. Estudou na Escola Politécnica do Rio de Janeiro, quando aderiu ao positivismo e o introduziu no país, sendo um dos fundadores da Sociedade Positivista Brasileira, em 1876. Em viagem à Europa, aderiu à linha de Augusto Comte, tornando-se aspirante ao Sacerdócio da Humanidade. Voltando ao Brasil, trouxe novas determinações às atividades da sociedade, passando depois a dirigir o Apostolado. Publicou com Teixeira Mendes "O Apostolado Positivista no Brasil". Deixou várias obras, como Pequenos Ensaios Positivistas, Luís de Camões, A Questão de Limites entre o Brasil e a Argentina, Ortografia Positivista e muitas outras. Em 1903, já doente, passou a chefia do Apostolado ao amigo
} 
Raimundo Teixeira Mendes. Faleceu afastado da militância positivista, aos 63 anos, na cidade de Petrópolis (CRUZ COSTA, 1967)

iiRaimundo Teixeira Mendes (1855-1927), maranhense, nasceu de família abastada. Seu pai era engenheiro pela Escola Central de Paris. Educou-se no catolicismo, assumindo desde o início o papel de formulador do ensino e dos escritos do Apostolado. No Rio de Janeiro, estudou no Colégio dos Jesuítas, demonstrando especial interesse pela Matemática e pela Filosofia. Como havia assumido os ensinamentos católicos, assumiu os dogmas de Comte, convertido por Miguel Lemos, que logo se dedicou a corrigir os rumos da sociedade positivista, dedicando-se à ortodoxia comtiana (CRUZ COSTA, 1967, p. 128).

iii Atualmente, a Igreja Positivista do Brasil realiza reuniões públicas todos os domingos às 10 horas da manhã, em seus templos no Rio de Janeiro, Curitiba e Porto Alegre, sendo que qualquer pessoa pode contribuir para a sua manutenção, não necessitando, portanto, ser positivista para fazer tal ato. A IPB está localizada à Rua Benjamin Constant, 74, Glória, Rio de Janeiro. Sua sede, também conhecida como Templo da Humanidade, foi o primeiro edifício construído no mundo para difundir a Religião da Humanidade. Todos os domingos, as 10h00, seus membros organizam conferências com hasteamento das bandeiras nacionais do Brasil e da França. Ao longo do ano, realizam Ciclo de Palestras e Conferências sob o nome "Em guarda pelo BRASIL". Entre os temas estão:" Em guarda "Pela Soberania Nacional, "Em guarda", pela Amazônia, "Em guarda" por Furnas, "Em guarda" pela Petrobrás, "Em guarda" pela Bandeira Republicana, "Em guarda" pela educação fundamental, "Em guarda" pelas liberdades constitucionais,"Em guarda " pela legislação trabalhista e " Em guarda " pelo presidencialismo.

iv A Sociedade Positivista, até 1883 se reunia muito raramente, com o retorno de Miguel Lemos, passou a se reunir todos os domingos. Em 1878, Lemos assume a direção do núcleo positivista do Rio de Janeiro, das mãos de Ribeiro Mendonça, instaurando mudanças importantes na organização e funcionamento da entidade, tornadas públicas na Primeira Circular Anual do Apostolado Positivista do Brasil. A partir dessa data, o núcleo positivista teria um importante crescimento de 5 colaboradores em 1878, para 55 em 1881, número que cresceria até 1891, quando atingiu 174. À frente do Apostolado, Miguel Lemos passou a adotar as regras traçadas por Augusto Comte, com Estatuto específico sobre seus objetivos, baseado no Manifesto Inicial da Sociedade Positivista de Paris, em 1848. A então Sociedade Positivista passou a denominar-se Igreja Positivista do Brasil, devendo seguir as diretrizes essenciais dos ensinamentos de Comte. (CRUZ COSTA, 1967, p. 166 -167).

${ }^{\vee} \mathrm{Na}$ década de noventa do século XIX, já se faziam ouvir, nos discursos da época, expressões até então desconhecidas, como "anarquia mental", "pedantocracia", "ordem", "progresso", "incorporação do proletariado", "reforma social". Mas, foi a partir do aforismo de que "o homem se agita e a humanidade o conduz" que o Apostolado Positivista do Brasil foi aos poucos construindo um clima de adesão ao positivismo nos diferentes segmentos da sociedade brasileira.

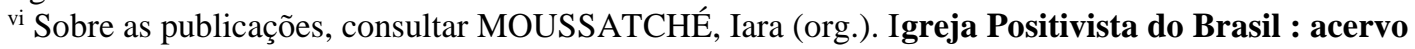
bibliográfico compilado por Iara Moussatché 2. ed. Rev. Ampl. Rio de Janeiro: Museu da República, 1994. LEAL, Elisabete da Costa; PEZAT, Paulo Ricardo. Capela Positivista de Porto Alegre: acervo bibliográfico, documental e iconográfico. Porto Alegre: FUMPROARTE -Programa de Pós-Graduação em História da UFRGS, 1996.

vii Idem, p. 165.

viii $\mathrm{O}$ referido texto consistiu no relatório inicial das atividades do Apostolado, encaminhado a Pierre Laffitte e publicado em 1981, em comemoração ao primeiro centenário da fundação da Igreja Positivista do Brasil. Em 1883, Miguel Lemos anuncia rompimento com Laffitte e assume definitivamente o comando do Apostolado no Brasil.

ix Neste texto, transformado em seguida, na Primeira Circular Anual da Igreja Positivista, Lemos traça um breve panorama sobre as origens e a constituição do Apostolado, ao mesmo instante em que realiza uma análise crítica das ações, ao longo dos primeiros cinco anos de existência do Apostolado entre 1876 a 1881. Cf. Resumo histórico do movimento positivista no Brasil.

${ }^{x}$ LEMOS, Miguel. Op. cit. p. 60.

${ }^{x i}$ LEMOS, Miguel. Resumo histórico do movimento positivista no Brasil p. 20.

xii Cf. PAIM, A. Idem, p. 4.

xiii Cf. LINS, Ivan. História do positivismo no Brasil.

Recebido em: $12 / 04 / 2017$

Aceito em: 15/08/2017 